\title{
Glycerol-Based Co-Oligomers by Free-Radical Chain Transfer Polymerization: Towards Reactive Polymers Bearing Acetal and/or Carbonate Groups with Enhanced Properties
}

Phuoc Dien Pham, ${ }^{a}$ Sophie Monge, ${ }^{a}$ Vincent Lapinte, ${ }^{\text {a* }}$ Yann Raoul, ${ }^{\mathrm{b}}$ Jean Jacques Robin ${ }^{\mathrm{a}}$

${ }^{a}$ Institut Charles Gerhardt Montpellier UMR5253 CNRS-UM-ENSCM -

Equipe Ingénierie et Architectures Macromoléculaires, Université

Montpellier - Bat 17 - cc1702, Place Eugène Bataillon 34095 Montpellier

cedex 5, France

${ }^{b}$ ONIDOL 11, rue de Monceau CS 6000375378 Paris cedex 08, France

e mail: vincent.lapinte@umontpellier.fr

\begin{abstract}
Oligomers coming from glycerin carbonate acrylate (GCA) and solketal acrylate (SolA) were synthesized in good yields by free-radical chain transfer polymerization using 2-mercaptoethanol (ME) as chain transfer agent. These oligomers were totally soluble in solvents and did not exhibit branching or gelation. The efficiency of the chain transfer polymerization process on these glycerolbased acrylate monomers was demonstrated and reactive cotelomers bearing both acetal and cyclocarbonate groups were obtained. The structure of these oligomers was well-characterized by NMR, SEC, FTIR and MALDI-Tof spectroscopies. The oligo(GC-stat-Sol)s are particularly interesting, notably in terms of reactivity and solubility in various organic solvents and water that can be modulated by varying different SolA/GCA ratios. These results open the way to a widespread valorization of glycerol.
\end{abstract}

KEYWORDS: Glycerol, hydrolysis, oligomers, radical polymerization.

$\dagger$ †lectronic Supplementary Information (ESI) available: [characterization by ${ }^{1} \mathrm{H}$ NMR and FTIR spectroscopy]. 


\section{Introduction}

Glycerol is one of the most important feedstock in the modern oleochemical industry[1, 2]. Byproduct in the production of biodiesel from vegetable oils, it results from saponification of fats. Due to its competitive cost, worldwide availability, and built-in functionality, glycerin and its derivatives become useful for numerous commercial applications. As production of glycerin is nowadays exceeding the demand, the valorization of the latter has emerged as a challenging trend [3]. As a result, glycerol can be used in the industry as an intermediate in the synthesis of numerous compounds (glycerin carbonate (GC), acrylic acid, solketal (Sol), ...)[4]. Moreover, GC was also employed as solvent[5], surfactant[6] or in the synthesis of polyurethanes[7], and polyethers[8]. In addition, it was used in pharmaceutical or cosmetic fields[9] thanks to its low vapor pressure, flammability, and toxicity, good biodegradability and moisturizing ability[2]. The cyclic carbonate function also brings high polarity and coordinating properties giving applications as electrolyte liquid carrier[10-14].

Monomers such as glycerin carbonate acrylate (GCA) and solketal acrylate (SolA) are interesting in the area of biosourced materials because their precursors (i.e. glycerin carbonate, acrylic acid) can be synthesized from glycerol ${ }^{[3]}$. Glycerin carbonate (meth)acrylate has already been involved in the synthesis of polymers ${ }^{[15]}$. Some syntheses were successful, $[16,17]$ but in most cases, resulting homopolymers were insoluble. $[15,18]$ This was attributed to the abstraction of a proton attached to the carbonate ring which led to chain branching and gelation. The solvent also influenced the polymerization[19]. These side-reactions have been largely detailed by Decker et al. [20, 21] and explained by Caillol et al. [22, 23]. So, homopolymers with high molecular weights cannot be reached with these monomers limiting their interest and only their copolymerization can be envisaged to get high molar masses. In the present contribution, we focused on low molecular weight polymers from these monomers, thus avoiding transfer reactions occurring for high conversion rates or high molecular weights and leading to soluble polymers. This strategy was previously performed in the design of surfactants using telogens exhibiting long alkyl chains as hydrophobic part[24].

The objective of this paper deals with the synthesis of (co)oligomers from glycerin carbonate acrylate and solketal acrylate without the use of any other (co)monomers and any branching or gelation limiting their solubility. These (co)oligomers are interesting due to the specific reactivity of the acetal and carbonate rings. But in the case of (co)oligomers exhibiting both rings, the question was to deprotect selectively one of the two rings. Herein, we focused on these (co)oligomers, precursors of polyhydroxyurethanes using carbonate rings and precursors of highly hydrophobic polymers bearing vicinal diols after the deprotection of acetal groups. Such (co)oligomers are promising in the field of polyhydroxyurethane hydrogels.

These (co)oligomers were prepared by radical chain transfer polymerization as largely investigated by B. Boutevin[25-27]. In this oligomerization process, a molecule YZ, named telogen, reacts onto 
propagating chains of monomer $\mathrm{M}$ to form telomers of general formula $\mathrm{Y}(\mathrm{M})_{\mathrm{n}} \mathrm{Z}$ with a low number of monomer units $(n<100)$. In this contribution, we report the first free-radical chain transfer polymerization of GCA and SolA monomers in the presence of 2-mercaptoethanol[28-30] (ME) and AIBN. The transfer constant of ME was determined in each case. The resulting oligomers (oligoGC, oligoSol, and oligo(GC-stat-Sol)s) were characterized by NMR and FTIR spectroscopies, SEC and MALDI-Tof. The solubility in numerous organic solvents of oligoSol, oligoGC and oligo(GC-statSol)s with various GCA and SolA ratios was determined as well as their thermal properties by DSC technique. At last, the selective deprotection of either carbonate ring or acetal group was envisaged leading to functional oligomers finding applications in the aforementioned areas. 


\section{Experimental section}

\section{Materials}

Acryloyl chloride (97\%), triethylamine and 2-mercaptoethanol (ME) were purchased from Aldrich and were used as received. Acetonitrile and dichloromethane were dried and distilled according to standard procedures. Deuterated solvents were purchased from SDS and were used without further purification. Glycerin carbonate (GC) and D,L-1,2-isopropylidenglycerin (Solketal) were a generous gift from ONIDOL. 2.2'-Azobisisobutyronitrile (AIBN) was purified twice by recrystallization in methanol and dried under vacuum. Commercially available reagents and solvents were purified and dried by standard methods prior to use.

\section{Analytical Techniques}

${ }^{1} \mathrm{H}$ and ${ }^{13} \mathrm{C}$ NMR spectra were recorded using a Bruker AC 300. Size exclusion chromatography (SEC) analysis in THF as eluent at a flow rate of $1 \mathrm{~mL} \cdot \mathrm{min}^{-1}$ was performed at $30{ }^{\circ} \mathrm{C}$ using a system equipped with a guard column and PLGel 500, 103, $10^{4}$ columns (Polymer Laboratories) connected in series. The molecular weight calibration curve was obtained using poly(methylmethacrylate) (PMMA) standards from Polymer Laboratories. Size exclusion chromatography (SEC) in DMF was performed on a Spectra-Physics apparatus equipped with an RI Shodex refractive index detector. Two PL-gel mix $\mathrm{C}$ columns were used at $70{ }^{\circ} \mathrm{C}$ with a flow rate of $0.8 \mathrm{~mL} \cdot \mathrm{min}^{-1}$ in DMF $(0.1 \% \mathrm{LiBr})$, calibrated using PMMA standards. Fourier Transform Infrared (FTIR) spectra were recorded with a Perkin-Elmer spectrum 100 spectrometer equipped with an attenuated total reflectance (ATR) crystal. Differential scanning calorimetry (DSC) analysis of the samples was carried out on 5-10 mg samples in aluminum pans, using a Mettler Toledo apparatus. The samples were heated at $10{ }^{\circ} \mathrm{C} / \mathrm{min}$, and cooled at the same rate to room temperature. The samples were then heated at $10^{\circ} \mathrm{C} / \mathrm{min}$.

Mass spectrometry analyses were conducted with a Bruker Ultra-Flex MALDI-Tof mass spectrometer equipped with a nitrogen laser (LSI, $337 \mathrm{~nm}, 10 \mathrm{~ns}$ pulse length) and one detector. Mixture of peptides was used for external calibration. The ions were accelerated by a potential of $25 \mathrm{kV}$ and reflected with a $26.3 \mathrm{kV}$ potential. All measurements were recorded in the reflection mode using $\alpha$-cyano-4hydroxycinnamic acid (HCCA) as matrix with NaI. For each spectrum 300 transients were accumulated. The resolution at $\mathrm{m} / z=1650$ was 331 . The polymer was dissolved in appropriated solvent at a concentration of $10 \mathrm{mg} \cdot \mathrm{mL}^{-1}$.

\section{Synthesis of (2-oxo-1,3-dioxolan-4-yl)methyl acrylate (Glycerin Carbonate Acrylate: GCA)}

4-(Hydroxymethyl)-1,3-dioxolan-2-one (Glycerin carbonate-GC) (85.44 g, $724 \mathrm{mmol})$ and triethylamine $(78.30 \mathrm{~g}, 774 \mathrm{mmol})$ were dissolved in dry dichloromethane $(500 \mathrm{~mL})$ and the solution was cooled in an ice bath under $\mathrm{N}_{2}$ for $15 \mathrm{~min}$. Dichloromethane solution $(200 \mathrm{~mL})$ of acryloyl 
chloride ( $66.84 \mathrm{~g}, 738 \mathrm{mmol}$ ) was added dropwise to the previous solution over a period of $2 \mathrm{~h}$. After stirring for $1 \mathrm{~h}$ at $0{ }^{\circ} \mathrm{C}$, the mixture was then allowed to warm up to room temperature and stirred further for $8 \mathrm{~h}$. The white precipitated by-product was filtered off and the clear product solution was washed with water $(3 \times 200 \mathrm{~mL})$, and brine $(2 \times 100 \mathrm{~mL})$, dried over anhydrous $\mathrm{Na}_{2} \mathrm{SO}_{4}$, filtered, and evaporated under reduced pressure to yield GCA as a yellow oil (99.62 g, $80 \%)$.

${ }^{1} \mathrm{H} \mathrm{NMR}\left(\mathrm{CDCl}_{3}, 300 \mathrm{MHz}\right) \delta(\mathrm{ppm}): 4.25-4.41\left(3 \mathrm{H}, \mathrm{H}_{2}\right.$ and $\left.\mathrm{H}_{4}\right), 4.51-4.56\left(1 \mathrm{H}, \mathrm{H}_{2}\right), 4.93\left(1 \mathrm{H}, \mathrm{H}_{3}\right)$,

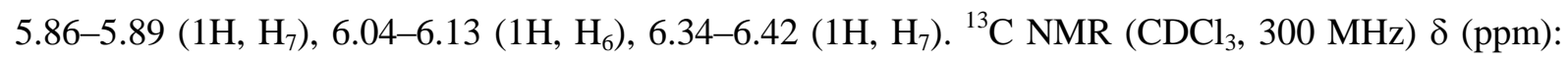
$63.2(\mathrm{C} 2), 66.1\left(\mathrm{C}_{4}\right), 74.0(\mathrm{C} 3), 127.2\left(\mathrm{C}_{6}\right), 132.3\left(\mathrm{C}_{7}\right), 154.7\left(\mathrm{C}_{1}\right), 165.3\left(\mathrm{C}_{5}\right)$. FTIR $\left(\mathrm{cm}^{-1}\right): 1159(\mathrm{C}-$ O), $1722(\mathrm{O}-(\mathrm{C}=\mathrm{O})), 1787$ (O-C(=O)-O), $2989(\mathrm{C}-\mathrm{H})$.

\section{Synthesis of (2,2-dimethyl-1,3-dioxolan-4-yl)methyl acrylate (Solketal Acrylate: SolA)}

(2,2-Dimethyl-1,3-dioxolan-4-yl)methanol (Solketal: Sol) $(79.8 \mathrm{~g}, 602.5 \mathrm{mmol})$ and triethylamine $(67.1 \mathrm{~g}, 663.3 \mathrm{mmol})$ were dissolved in dry dichloromethane $(400 \mathrm{~mL})$ and the solution was cooled in an ice bath under $\mathrm{N}_{2}$ for $15 \mathrm{~min}$. Dichloromethane solution $(200 \mathrm{~mL})$ of acryloyl chloride $(55.7 \mathrm{~g}, 615$ mmol) was added dropwise to the previous solution over a period of $2 \mathrm{~h}$. After stirring for $1 \mathrm{~h}$ at $0{ }^{\circ} \mathrm{C}$, the mixture was then allowed to warm up to room temperature and stirred further for $8 \mathrm{~h}$. The white precipitated by-product was filtered off and the clear product solution was washed with water $(3 x 200$ $\mathrm{mL})$, and brine $(2 \times 100 \mathrm{~mL})$, dried over anhydrous $\mathrm{Na}_{2} \mathrm{SO}_{4}$, filtered, and evaporated under reduced pressure to afford SolA as a yellow oil $(95.49 \mathrm{~g}, 85 \%)$. The product was used in next step without further purification.

${ }^{1} \mathrm{H}$ NMR $\left.\left(\mathrm{CDCl}_{3}, 300 \mathrm{MHz}\right) \delta(\mathrm{ppm}): 1.35\left(3 \mathrm{H}, \mathrm{H}_{1} / \mathrm{H}_{2}\right), 1.42(3 \mathrm{H}), \mathrm{H}_{1} / \mathrm{H}_{2}\right), 3.76\left(\mathrm{H}_{4}\right), 4.05-4.35\left(\mathrm{H}_{4}\right.$,

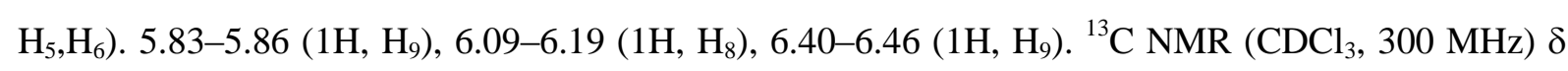
(ppm): $25.1\left(\mathrm{C}_{1} / \mathrm{C}_{2}\right), 26.5\left(\mathrm{C}_{1} / \mathrm{C}_{2}\right), 64.5\left(\mathrm{C}_{4}\right), 66.1\left(\mathrm{C}_{6}\right), 73.4\left(\mathrm{C}_{5}\right), 109.5\left(\mathrm{C}_{3}\right), 127.9\left(\mathrm{C}_{8}\right), 131.0\left(\mathrm{C}_{9}\right)$, $165.4\left(\mathrm{C}_{7}\right)$. FTIR $\left(\mathrm{cm}^{-1}\right): 1183(\mathrm{C}-\mathrm{O}), 1725(\mathrm{O}-(\mathrm{C}=\mathrm{O})), 2887-2988(\mathrm{C}-\mathrm{H})$.

\section{Chain transfer polymerization of GCA: Synthesis of OligoGC}

Chain transfer polymerization of GCA was performed in acetonitrile in presence of ME with different molar ratios $\mathrm{R}_{0}\left(\mathrm{R}_{0}=\mathrm{n}_{\text {telogen }} / \mathrm{n}_{\text {monomer }}\right)$ from $0.05,0.1,0.2$ and 0.3. GCA (8.6 g, $\left.50 \mathrm{mmol}\right)$ and $\mathrm{ME}$ $(0.3906 \mathrm{~g}, 5 \mathrm{mmol})$ were introduced in a $100 \mathrm{~mL}$ two necked flask equipped with a condenser and a septum. The solution was diluted to $50 \mathrm{~mL}$ with anhydrous acetonitrile. The solution was bubbled with nitrogen for $30 \mathrm{~min}$ before heating at $80{ }^{\circ} \mathrm{C}$. Finally AIBN $(0.041 \mathrm{~g}, 0.25 \mathrm{mmol})\left(\mathrm{C}_{0}=\mathrm{n}_{\text {initiator }} / \mathrm{n}_{\text {monomer }}\right.$ $=0.5 \%$ ) in $1 \mathrm{~mL}$ of anhydrous acetonitrile was added through the septum with a syringe. After $8 \mathrm{~h}$ of reaction, the polymer was precipitated in cold ethanol to remove the unreacted monomer and telogen, filtered and then dried under vacuum.

${ }^{1} \mathrm{H}$ NMR $\left.\left(\mathrm{CD}_{3} \mathrm{CN}, 300 \mathrm{MHz}\right) \delta(\mathrm{ppm}): 1.57-1.89\left((2 \mathrm{H}) \mathrm{n}, \mathrm{H}_{7}\right), 2.38-2.60(1 \mathrm{H}) \mathrm{n}, \mathrm{H}_{6}\right), 2.75\left(2 \mathrm{H}, \mathrm{H}_{8}\right)$, 
$3.64\left(2 \mathrm{H}, \mathrm{H}_{9}\right), 4.20-4.5\left((3 \mathrm{H}) \mathrm{n}, \mathrm{H}_{2}, \mathrm{H}_{4}\right), 4.55-4.72\left((1 \mathrm{H}) \mathrm{n}, \mathrm{H}_{2}\right), 5.02\left((1 \mathrm{H}) \mathrm{n}, \mathrm{H}_{3}\right) .{ }^{13} \mathrm{C} \mathrm{NMR}\left(\mathrm{CD}_{3} \mathrm{CN}\right.$, $300 \mathrm{MHz}) \delta(\mathrm{ppm}): 34.3\left(\mathrm{C}_{7}\right), 40.9\left(\mathrm{C}_{6}\right), 63.3\left(\mathrm{C}_{2}\right), 65.9\left(\mathrm{C}_{4}\right), 74.0\left(\mathrm{C}_{3}\right), 154.7\left(\mathrm{C}_{1}\right), 173.6\left(\mathrm{C}_{5}\right), \mathrm{C}_{8}, \mathrm{C}_{9}$ (not attributable). FTIR ( $\left.\mathrm{cm}^{-1}\right)$ : $1155(\mathrm{C}-\mathrm{O}), 1731(\mathrm{O}-(\mathrm{C}=\mathrm{O})), 1785(\mathrm{O}-\mathrm{C}(=\mathrm{O})-\mathrm{O}), 2958(\mathrm{C}-\mathrm{H}), 3546$ $(\mathrm{OH})$.

\section{Chain transfer polymerization of SolA: Synthesis of OligoSol}

Chain transfer polymerization was performed with SolA monomer in acetonitrile in presence of ME as telogen with different molar ratios $\mathrm{R}_{0}\left(\mathrm{R}_{0}=\mathrm{n}_{\text {telogen }} / \mathrm{n}_{\text {monomer }}\right)$ from $0.05,0.1,0.2$ and 0.3. SolA (9.3 $\mathrm{g}, 50$ $\mathrm{mmol})$ and $\mathrm{ME}(0.3906 \mathrm{~g}, 5 \mathrm{mmol})$ were introduced in a $100 \mathrm{~mL}$ two necked flask equipped with a condenser and a septum and the solution was diluted to $50 \mathrm{~mL}$ of anhydrous acetonitrile. The solution was bubbled with nitrogen for $30 \mathrm{~min}$ before heating at $80{ }^{\circ} \mathrm{C}$. Finally, AIBN $(0.041 \mathrm{~g}, 0.25 \mathrm{mmol})$ $\left(\mathrm{C}_{0}=\mathrm{n}_{\text {initiator }} / \mathrm{n}_{\text {monomer }}=0.5 \%\right)$ in $1 \mathrm{~mL}$ of anhydrous acetonitrile was added through the septum with a syringe. After $8 \mathrm{~h}$ of reaction, the polymer was precipitated in cold EtOH to remove the unreacted monomer and telogen, filtered and then dried under vacuum.

${ }^{1} \mathrm{H}$ NMR $\left(\mathrm{CD}_{3} \mathrm{CN}\right) \delta(\mathrm{ppm}): 1.40\left((3 \mathrm{H})_{\mathrm{m}}, \mathrm{H}_{1} / \mathrm{H}_{2}\right), 1.46\left((3 \mathrm{H})_{\mathrm{m}}, \mathrm{H}_{1} / \mathrm{H}_{2}\right), 1.60-2.60\left((3 \mathrm{H})_{\mathrm{m}}+2 \mathrm{H}, \mathrm{H}_{8}\right.$, $\left.\mathrm{H}_{9}, \mathrm{H}_{10}\right), 3.75-3.82\left((1 \mathrm{H})_{\mathrm{m}}+2 \mathrm{H}, \mathrm{H}_{4}\right.$ and $\left.\mathrm{H}_{11}\right), 4.10-4.13\left((3 \mathrm{H}) \mathrm{m}, \mathrm{H}_{4}\right.$ and $\left.\mathrm{H}_{6}\right), 4.34\left((1 \mathrm{H}) \mathrm{m}, \mathrm{H}_{5}\right) .{ }^{13} \mathrm{C}$ $\operatorname{NMR}\left(\mathrm{CDCl}_{3}, 300 \mathrm{MHz}\right) \delta(\mathrm{ppm}): 25.4\left(\mathrm{C}_{1} / \mathrm{C}_{2}\right), 26.8\left(\mathrm{C}_{1} / \mathrm{C}_{2}\right), 35.1\left(\mathrm{C}_{9}\right), 41.1\left(\mathrm{C}_{8}\right), 65.1\left(\mathrm{C}_{4}\right), 66.4$ $\left(\mathrm{C}_{6}\right), 73.5\left(\mathrm{C}_{5}\right), 109.6\left(\mathrm{C}_{3}\right), 174.1\left(\mathrm{C}_{7}\right), \mathrm{C}_{10}, \mathrm{C}_{11}$ (not attributable). FTIR $\left(\mathrm{cm}^{-1}\right)$ : $1156(\mathrm{C}-\mathrm{O}), 1731(\mathrm{O}-$ $(\mathrm{C}=\mathrm{O})), 2887-2985(\mathrm{C}-\mathrm{H}), 3463(\mathrm{OH})$.

\section{Cotelomerization of GCA and SolA: Synthesis of Oligo(GC-stat-Sol)}

Cotelomerization of GCA with SolA comonomer were performed in acetonitrile with a ratio GCA/SolA (50/50). In a typical chain transfer polymerization, GCA (0.86 g, $5 \mathrm{mmol})$, SolA (0.93 g, 5 $\mathrm{mmol})$ and $\mathrm{ME}(0.078 \mathrm{~g}, 1 \mathrm{mmol})$ were introduced in a $50 \mathrm{~mL}$ two necked flask equipped with a condenser and a septum and the solution was diluted to $10 \mathrm{~mL}$ with anhydrous acetonitrile. The solution was bubbled with nitrogen for $30 \mathrm{~min}$ before heating at $80{ }^{\circ} \mathrm{C}$. Finally, AIBN $(0.0164 \mathrm{~g}, 0.1$ mmol $)\left(\mathrm{C}_{0}=\mathrm{n}_{\text {initiator }} / \mathrm{n}_{\text {monomer }}=1 \%\right)$ in $1 \mathrm{~mL}$ of anhydrous acetonitrile was added through the septum with a syringe. After $10 \mathrm{~h}$, the copolymer was precipitated in cold ethanol to remove the unreacted monomer and telogen, filtered and then dried under vacuum.

${ }^{1} \mathrm{H}$ NMR $\left(\mathrm{CD}_{3} \mathrm{CN}, 300 \mathrm{MHz}\right) \delta(\mathrm{ppm}): 1.37\left((3 \mathrm{H})_{\mathrm{m}}, \mathrm{H}_{15} / \mathrm{H}_{16}\right), 1.43\left((3 \mathrm{H})_{\mathrm{m}}, \mathrm{H}_{15} / \mathrm{H}_{16}\right), 1.45-2.60$ $\left((3 \mathrm{H}) \mathrm{n}+(3 \mathrm{H}) \mathrm{m}, \mathrm{H}_{6}, \mathrm{H}_{7}, \mathrm{H}_{8}\right.$ and $\left.\mathrm{H}_{9}\right), 2.78\left(2 \mathrm{H}, \mathrm{H}_{17}\right), 3.66\left(2 \mathrm{H}, \mathrm{H}_{18}\right), 3.74-3.81\left((1 \mathrm{H}) \mathrm{m}, \mathrm{H}_{12}\right), 4.07-4.35$ $\left((3 \mathrm{H}) \mathrm{n}+\left((4 \mathrm{H}) \mathrm{m}, \mathrm{H}_{2}, \mathrm{H}_{4}, \mathrm{H}_{11}, \mathrm{H}_{12}\right.\right.$ and $\left.\mathrm{H}_{13}\right), 4.59-4.67\left((1 \mathrm{H}) \mathrm{n}, \mathrm{H}_{2}\right), 5.03\left((1 \mathrm{H}) \mathrm{n}, \mathrm{H}_{3}\right) .{ }^{13} \mathrm{C} \mathrm{NMR}\left(\mathrm{CD}_{3} \mathrm{CN}\right.$, $300 \mathrm{MHz}) \delta(\mathrm{ppm}): 24.3\left(\mathrm{C}_{15} / \mathrm{C}_{16}\right), 25.7\left(\mathrm{C}_{15} / \mathrm{C}_{16}\right), 34.1\left(\mathrm{C}_{7}, \mathrm{C}_{8}\right), 40.7\left(\mathrm{C}_{6}, \mathrm{C}_{9}\right), 63.2\left(\mathrm{C}_{2}\right), 64.3\left(\mathrm{C}_{12}\right)$, $65.7\left(\mathrm{C}_{11}\right), 66.1\left(\mathrm{C}_{4}\right), 72.8\left(\mathrm{C}_{13}\right), 73.8\left(\mathrm{C}_{3}\right), 108.8(\mathrm{C} 14), 154.5\left(\mathrm{C}_{1}\right), 173.4\left(\mathrm{C}_{5} / \mathrm{C}_{10}\right), 173.6\left(\mathrm{C}_{5} / \mathrm{C}_{10}\right)$, $\mathrm{C}_{17}, \mathrm{C}_{18}$ (not observed). FTIR $\left(\mathrm{cm}^{-1}\right): 1153(\mathrm{C}-\mathrm{O}), 1731(\mathrm{O}-(\mathrm{C}=\mathrm{O})), 1792(\mathrm{O}-\mathrm{C}(=\mathrm{O})-\mathrm{O}), 2939-2986$ (C-H), $3533(\mathrm{OH})$. 


\section{Chain transfer polymerization kinetics}

All the kinetics were studied following the monomer and telogen concentrations versus reaction time. Each reaction was monitored by sampling and each aliquot was quenched in liquid nitrogen in order to stop the reaction. The thiol conversion of each sample was evaluated using titration of the SH groups with a 0.002 mol. $\mathrm{L}^{-1}$ iodine solution prepared from iodine standard solution $\left(0.105 \mathrm{~mol} . \mathrm{L}^{-1}\right)$ according to the following equation:

$2 \mathrm{RCH}_{2} \mathrm{SH}+\mathrm{I}_{2} \longrightarrow \mathrm{RCH}_{2} \mathrm{SSCH}_{2} \mathrm{R}+2 \mathrm{H}^{\oplus}+21^{\ominus}$

The thiol concentration ([RSH]) versus time is given by the following equation:

$[R S H] t=\frac{\mathrm{Veq}_{\mathrm{I}_{2}} \mathrm{x}\left[\mathrm{I}_{2}\right]}{\mathrm{V}_{\mathrm{RSH}}}$

where $\mathrm{Veq}_{\mathrm{I}}$ is the volume of iodine solution added to the thiol solution at $\mathrm{t} \mathrm{min}, \mathrm{V}_{\mathrm{RSH}}$ is the volume of thiol sample withdrawn from the reaction mixture. $\left[I_{2}\right]$ is the concentration of the iodine solution used for the titration. $[\mathrm{RSH}]_{\mathrm{t}}$ is the concentration of thiol solution at $\mathrm{t}$ min.

The monomer consumption was calculated by ${ }^{1} \mathrm{H}$ NMR with $\mathrm{CD}_{3} \mathrm{CN}$ as deuterated solvent. Each sample was analyzed by comparing the integration ratio of the monomer to that of the polymer one.

$$
\operatorname{Ln} \frac{[M E]_{0}}{[M E]_{t}}=\mathrm{C}_{\mathrm{t}} \cdot \operatorname{Ln} \frac{[M]_{0}}{[M]_{t}}
$$

where $[\mathrm{ME}]$ and $[\mathrm{M}]$ are the concentration of telogen and monomer at $\mathrm{t}=0$ and $\mathrm{t}$. 


\section{Results and discussion}

Both glycerol-based precursors bearing carbonate (GC) or acetal group (Sol) as reactive groups are commercially available. The treatment of GC and Sol with acryloyl chloride in the presence of triethylamine in dichloromethane at room temperature for $8 \mathrm{~h}$ afforded GCA and SolA monomers in 80 and $85 \%$ yield, respectively (Scheme 1 ). These monomers were well-described by ${ }^{1} \mathrm{H}$ and ${ }^{13} \mathrm{C}$ NMR spectroscopies regarding the integration of the acrylic protons perfectly correlated with those of the acetal or cyclocarbonate rings (supporting information).

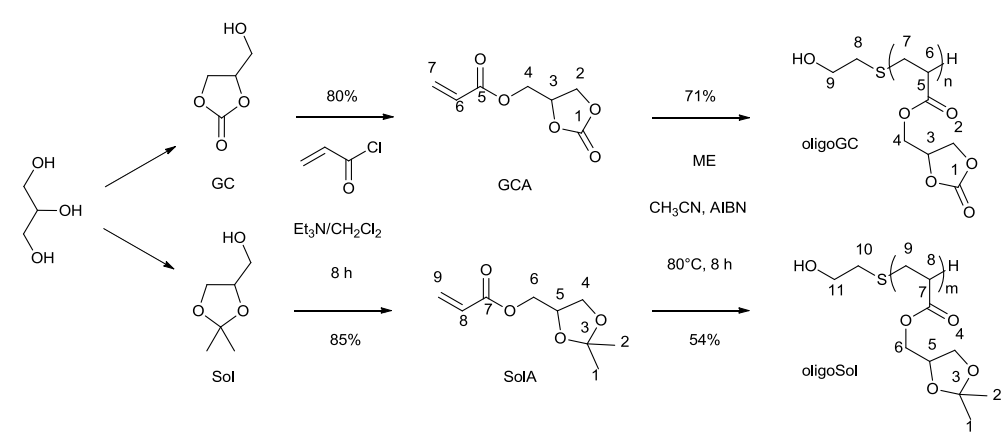

Scheme 1. Synthesis and chain transfer polymerization of GCA and SolA monomers.

\section{Homotelomerization}

The free-radical telomerization of GCA and SolA was performed in acetonitrile in the presence of AIBN and ME as telogen at $80{ }^{\circ} \mathrm{C}$ for $8 \mathrm{~h}$ with different molar ratios $\mathrm{R}_{0}\left(\mathrm{R}_{0}=\mathrm{n}_{\text {telogen }} / \mathrm{n}_{\text {monomer }}\right)$ ranging from 0.05 to 0.3 (Scheme 1). In the first step of the telomerization process, the decomposition of AIBN further permits the formation of $\mathrm{S}^{\bullet}$ radical (coming from RSH) which then reacted with a M monomer unit to form radical species, starting a propagation step. The $S-(M)_{n-1} M^{\bullet}$ active chain then reacted with "S-H" to terminate the chain and reinitiate another radical $\mathrm{S}^{\bullet}$. The resulting oligoGC and oligoSol both carried a hydroxyl headgroup. In the case of GCA without AIBN, it was checked that $\mathrm{ME}$ could not react with the cyclocarbonate ring of GCA. No trace of by-product was detected by ${ }^{13} \mathrm{C}$ $\mathrm{NMR}$ and the characteristic peak of $\mathrm{C}=\mathrm{O}_{\text {cyclocarbonate }}$ at $154.7 \mathrm{ppm}$ remained intact. Moreover no decrease of the characteristic band of $\mathrm{C}=\mathrm{O}_{\text {cyclocarbonate }}$ at $1785 \mathrm{~cm}^{-1}$ was observed. The monomer consumption $(\alpha)$ was calculated from ${ }^{1} \mathrm{H} N M R$ in $\mathrm{CD}_{3} \mathrm{CN}$ in respect to the gradual disappearance of ethylenic protons (Figure 1). The $\alpha$ value was deduced from the integration of the characteristic peaks of $\mathrm{H}_{(6)}$ attributed to $\mathrm{CH}$ in $\alpha$ position of the double bond located at 5.95-5.98 ppm and that of $\mathrm{H}_{(3)}$ corresponding to $\mathrm{CH}$ in $\alpha$ position of cyclocarbonate at $5.02 \mathrm{ppm}$ using the following equation (supporting information).

$$
1-a=\frac{[G C A]_{t}}{[G C A]_{0}}=\frac{\int H_{6}(5.95-5.98 p p m)}{\int H_{3}(5.02 p p m)}
$$


The total consumption of GCA and SolA occurred in about 5-6 h. It is noteworthy that a high conversion, 95 and $90 \%$ respectively, of GCA and SolA into oligomers was reached. Besides, the consumption of the telogen agent was followed by iodide titration of aliquots taken throughout the reaction (see experimental part). As shown in Figure 1, the monomer concentration decreased faster than the telogen one until four (GCA) and two hours of reaction (SolA), respectively. Then, both of them decreased simultaneously. Moreover for each monomer ME conversion was reached until 95\% yield. The reaction took place faster with GCA related to SolA, almost all GCA was consumed after one hour whereas more than three hours were required for SolA. Nevertheless, after 6 hours, monomer conversion was similar in both cases. This difference in reactivity was logically attributed to the acetal and carbonate groups but we did not find a satisfying explanation of these behaviors.
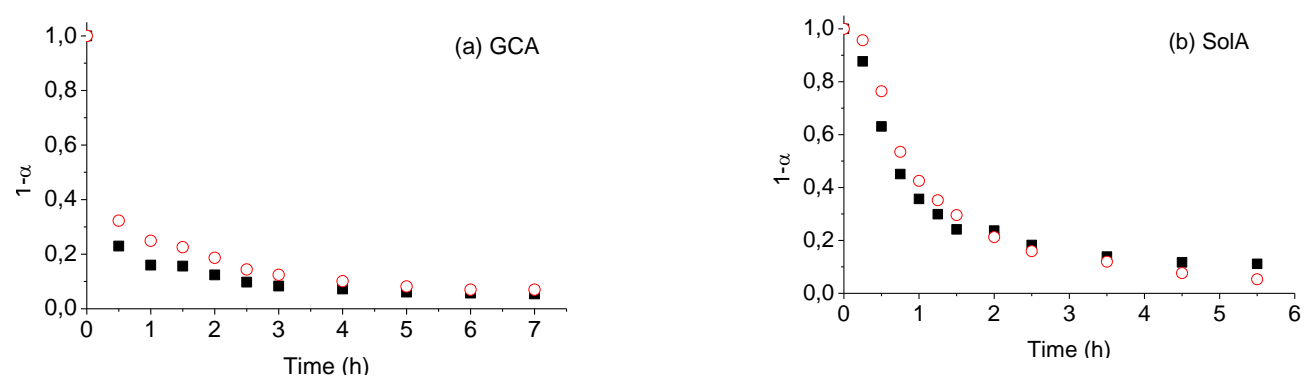

Figure 1. Consumption $(\alpha)$ of ME and monomer versus time ( $\mathbf{\square o n o m e r , ~} \bigcirc$ telogen) for the oligomerization of (a) GCA $\left(\mathrm{R}_{0}=0.1\right)$ and of (b) SolA $\left(\mathrm{R}_{0}=0.1\right)$.

In the kinetic study, oligoGC and oligoSol were synthesized with various $\mathrm{R}_{0}$ in order to check that $\mathrm{ME}$ was a good telogen for both monomers $\left(0<\mathrm{C}_{\mathrm{T}}\right.$ (chain transfer constant) $\left.<1\right)$. Among the numerous methods of $\mathrm{C}_{\mathrm{T}}$ determination, two methods could be retained: Mayo's method[31] and O'Brien's method.[32] In the first one, the $\mathrm{C}_{\mathrm{T}}$ value must be calculated at very low conversion whereas both monomer and telogen consumptions versus time are required to determine the $\mathrm{C}_{\mathrm{T}}$ values according to the O'Brien method. In our case, the O'Brien's method was selected after verifying the absence of classical polymerization reaction during the telomerization process. This method, very usually used for kinetic calculations is based on the total consumption of monomer and telogen without differentiation of the different steps occurring during the telomerization. This was achieved by size exclusion chromatography which did not reveal any trace ascribed to high molecular weight polymers. $\mathrm{C}_{\mathrm{T}}$ value was deduced from the slope of $\ln \left([\mathrm{ME}]_{0} /[\mathrm{ME}]_{t}\right)$ versus $\ln \left([\mathrm{M}]_{0} /[\mathrm{M}]_{t}\right)$ in the case of linear behavior (correlation coefficient: $\mathrm{R}^{2}>0.98$ ) (Figure 2).

$$
\ln \frac{[M E]_{0}}{[M E]_{t}}=C_{T} \cdot \ln \frac{[M]_{0}}{[M]_{t}}
$$

The $\mathrm{C}_{\mathrm{T}, \mathrm{GCA}}$ and $\mathrm{C}_{\mathrm{T}}$, SolA values ranged from 0.54 to 0.89 for various $\mathrm{R}_{0}$ with a good correlation coefficient of the linear relationship $\left(\mathrm{R}^{2}\right)$ close to $0.98-0.99$ (Table 1). It is interesting to notice that for GCA and SolA monomers the experimental $\mathrm{DP}_{\mathrm{n}}$ were closed from the theoretical ones. The $\mathrm{C}_{\mathrm{T}, \mathrm{GCA}}$ 
and $\mathrm{C}_{\mathrm{T} \text {, SolA }} \mathrm{C}_{\mathrm{T}}$ values $\left(\mathrm{C}_{\mathrm{T}}=0.54-0.89\right)$ lower than 1 meant that $\mathrm{ME}$ was an efficient transfer agent and that a control of the molecular weights was achieved. Moreover, whatever the monomer and for low $\mathrm{DP}_{\mathrm{n}}$, the transfer constant $\mathrm{C}_{\mathrm{T}}$ increased with chain length. Same kind of behavior has already been reported in the literature [33] [34]. $\mathrm{C}_{\mathrm{T} \text {, SolA }}$ and $\mathrm{C}_{\mathrm{T}, \mathrm{GCA}}$ were relatively similar which indicated that the nature of protecting groups had no influence on the transfer step (Table 1). The $\mathrm{C}_{\mathrm{T}}$ values depended on the [telogen]/[monomer] ratio and were consistent with values given in the literature.[33, 35] Molecular weights determined by ${ }^{1} \mathrm{H}$ NMR were in accordance with those targeted whereas they were slightly surestimated using SEC due to the use of DMF as eluent (PMMA standards). We noted that the chain length increased proportionally to the initial monomer concentration attesting the linear chain growth mechanism. Finally, polydispersity indexes $(\nexists)$ close to 1.4 were narrow and in accordance with values obtained for telomers. In summary, various lengths of oligoGC and oligoSol could be synthesized with a good control of the molecular weight thanks to the efficiency of ME as telogen.
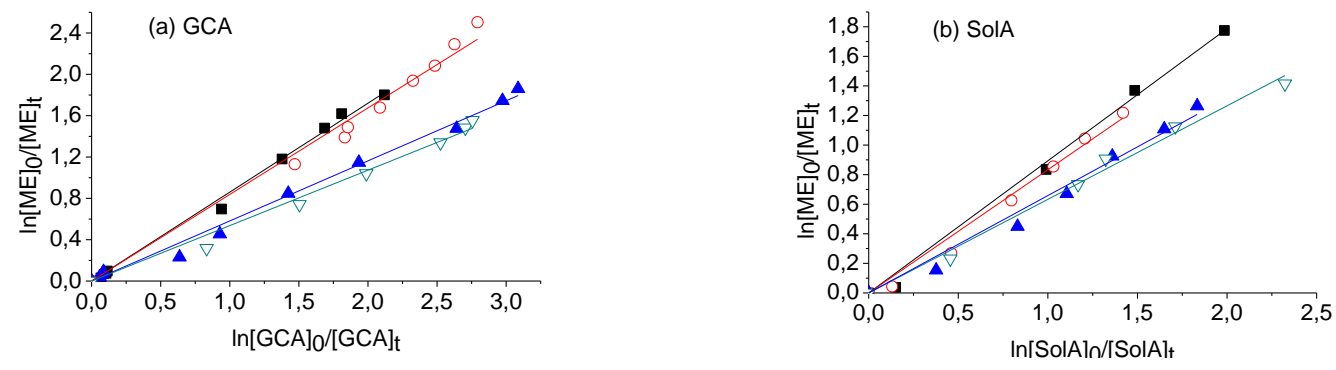

Figure 2. $\operatorname{Ln}\left([\mathrm{ME}]_{0} /[\mathrm{ME}]_{\mathrm{t}}\right)$ versus $\left.\operatorname{Ln}(\mathrm{M}]_{0} /[\mathrm{M}]_{\mathrm{t}}\right)$ for the polymerization of (a) GCA and (b) SolA for different $\mathrm{R}_{0}=(\boldsymbol{\square} 0.05, \bigcirc 0.1, \boldsymbol{\Delta} 0.2, \nabla 0.3)$.

Table 1. $C_{T}$ and $D P_{n}$ values according to $R_{0}$ for the telomerization of glycerin carbonate acrylate (GCA) and solketal acrylate (SolA) using 2-mercaptoethanol as chain transfer agent.

\begin{tabular}{|c|c|c|c|c|c|c|c|c|}
\hline $\mathbf{R}_{\mathbf{0}}{ }^{\mathrm{a}}$ & $\mathbf{M}$ & $\mathbf{C}_{T}^{b}$ & $\overline{\mathbf{R}^{2}}$ & $\overline{\mathrm{DP}}_{\mathrm{n}}^{\mathrm{th}}$ & $\overline{\overline{\mathrm{DP}}_{\mathrm{n}}^{\exp \mathrm{c}}}$ & $\overline{M_{n e x p}}$ & $M_{\text {nexp }}{ }^{d}$ & $\bar{\theta}^{\mathbf{d}}$ \\
\hline \multirow{2}{*}{0.05} & GCA & 0.86 & 0.995 & \multirow{2}{*}{20} & 23 & 4000 & 5800 & 1.48 \\
\hline & SolA & 0.89 & 0.994 & & 25 & 4400 & 4800 & 1.34 \\
\hline \multirow{2}{*}{0.1} & GCA & 0.84 & 0.983 & \multirow{2}{*}{10} & 13 & 2300 & 3900 & 1.39 \\
\hline & SolA & 0.83 & 0.984 & & $-{ }^{e}$ & $-{ }^{e}$ & $--^{\mathrm{e}}$ & $--^{\mathrm{e}}$ \\
\hline \multirow{2}{*}{0.2} & GCA & 0.58 & 0.992 & \multirow{2}{*}{5} & 6.5 & 1200 & 3100 & 1.28 \\
\hline & SolA & 0.66 & 0.981 & & $-{ }^{e}$ & $-{ }^{e}$ & $--^{e}$ & $-{ }^{e}$ \\
\hline \multirow{2}{*}{0.3} & GCA & 0.54 & 0.986 & \multirow{2}{*}{3.3} & 5 & 950 & 2500 & 1.24 \\
\hline & SolA & 0.63 & 0.991 & & $-\mathrm{-e}^{\mathrm{e}}$ & $-{ }^{e}$ & $--^{e}$ & $-{ }^{e}$ \\
\hline
\end{tabular}

SEC using DMF as eluent and PMMA standards; ${ }^{\mathrm{e}}$ non-precipitated. 
The structure of oligoGC and oligoSol was confirmed by MALDI-Tof mass spectroscopy (Figure 3). The spectra were recorded in reflectron mode using $\mathrm{Na}^{+}$cations in an $\alpha$-cyano-4-hydroxycinamic acid (HCCA) matrix. The detected ions were $\mathrm{MNa}^{+}$type. For oligoGC, a single distribution of peaks from $\mathrm{m} / \mathrm{z}$ was observed with an interval between two principal peaks being $172 \mathrm{~g} \mathrm{~mol}^{-1}$ corresponding to the molecular weight of the glycerin carbonate monomeric unit. Concerning the Maldi-Tof spectrum of the oligoSol, the main family was observed with $\Delta \mathrm{M}=186 \mathrm{~g} \mathrm{~mol}^{-1}$ corresponding to the molecular weight of the Solketal monomeric unit. The molar mass distribution was quite narrow in the case of oligoGC compared to the Gaussian one obtained for oligoSol. The nature of oligomer end-groups $(\mathrm{H}$ and $\mathrm{HOCH}_{2} \mathrm{CH}_{2} \mathrm{~S}$ end-groups) was confirmed demonstrating the efficiency of the telomerization process. In the case of oligoSol, a supplementary minor series was observed and could be attributed to HS-CH2-CH2-S-(oligomer)-S-CH2-CH2-OH, 2Na+ in agreement with the previous work of Boutevin on the telomerization in presence of mercaptoethanol and AIBN.[36] The MALDI-Tof also showed a good correlation between theoretical and experimental $M_{n}$ values, demonstrated the chemical stability of cyclocarbonate and acetal groups during free-radical reactions and the linear chain growth mechanism regarding the arithmetic evolution of peaks.

This was confirmed by FTIR spectroscopy which showed the remaining cyclocarbonate groups during the free-radical oligomerization since no significant decrease of the characteristic $\mathrm{C}=\mathrm{O}$ band at 1785 $\mathrm{cm}^{-1}$ (Supporting information). At last, the oligoGC were easily precipitated in cold ethanol whilst the oligoSol remained miscible in common organic solvents. As a consequence, precipitation of oligoSol was difficult for high $\mathrm{R}_{0}(0.1,0.2$ and 0.3$)$.
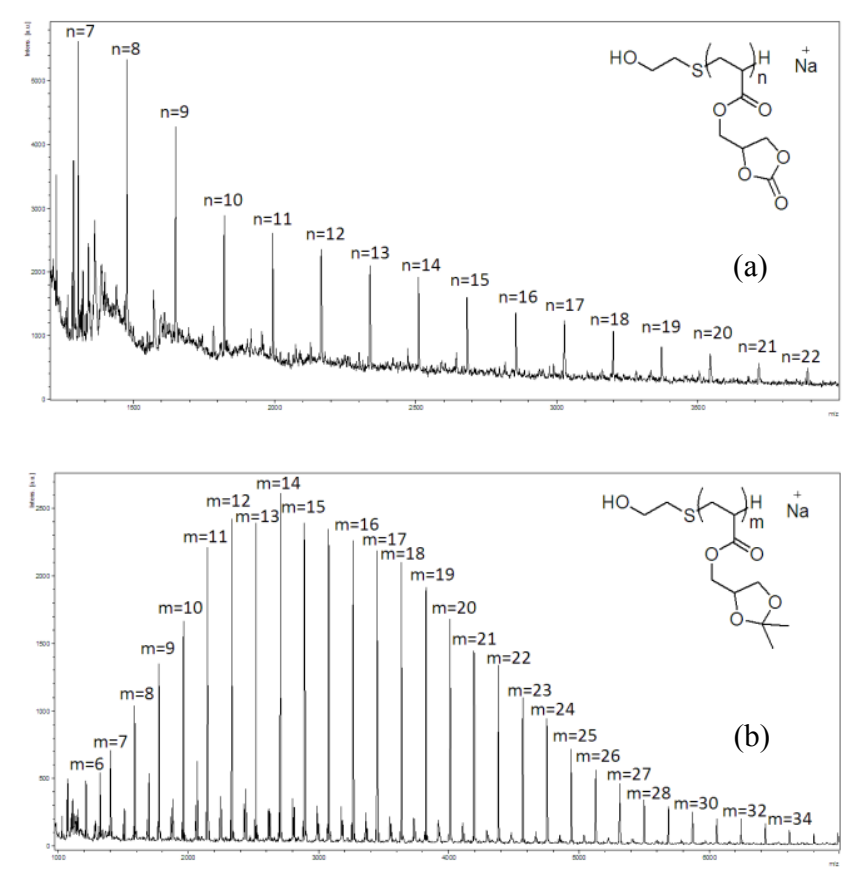

Figure 3. MALDI-Tof MS spectra of (a) oligoGC and (b) oligoSol using $\alpha$-cyano-4-hydroxycinamic acid (HCCA) matrix with NaI. 


\section{Cotelomerization of GCA and SolA: Synthesis of Oligo(GC-stat-Sol)s}

According to the target of the research, the cotelomerization between GCA and SolA was investigated to elaborate polymers exhibiting the reactivity of carbonate ring and the hydrophilicity of solketal after deprotection of the acetal group. As a result, a series of oligo(GC-stat-Sol)s bearing various GCA/SolA ratios were synthesized as shown in Table 2. The free-radical cotelomerization of GCA and SolA was performed in acetonitrile in the presence of telogen ME and AIBN at $80{ }^{\circ} \mathrm{C}$ for $10 \mathrm{~h}$ (Scheme 2).<smiles>C=CC(=O)OCC1COC(=O)O1</smiles>

GCA

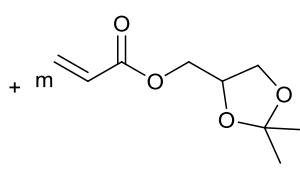

SolA

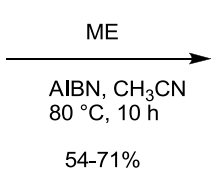

$54-71 \%$

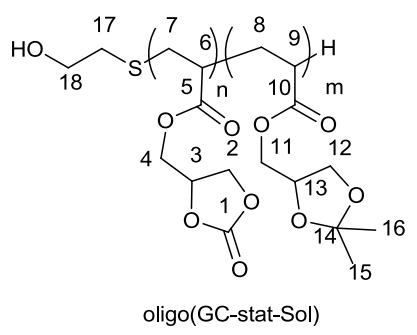

oligo(GC-stat-Sol)

Scheme 2. Cotelomerization of GCA and SolA in the presence of ME, achieved with different GCA/SolA ratios.

Table 2. Characterization of oligo(GC-stat-Sol)s prepared by telomerization using ME as telogen and AIBN as initiator.

\begin{tabular}{|c|c|c|c|c|c|c|c|}
\hline \multirow{2}{*}{$\begin{array}{c}\text { Theo. } \\
\text { GCA/SolA }^{\mathrm{a}}\end{array}$} & \multirow{2}{*}{$\begin{array}{c}\text { Exp. } \\
\text { GCA/SolA }^{b}\end{array}$} & \multirow{2}{*}{$\begin{array}{l}\text { Yield } \\
(\%)\end{array}$} & \multirow{2}{*}{$\begin{array}{c}\mathrm{M}_{\mathrm{n} \mathrm{NMR}} \\
\left(\mathrm{g} \cdot \mathrm{mol}^{-1}\right)\end{array}$} & \multicolumn{2}{|c|}{ SEC in THF } & \multicolumn{2}{|c|}{ SEC in DMF } \\
\hline & & & & 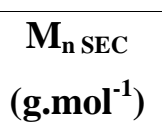 & $\boldsymbol{\theta}$ & $\begin{array}{c}\mathbf{M}_{\mathrm{n} \mathrm{SEC}} \\
\left(\text { g.mol }^{-1}\right)\end{array}$ & $\boldsymbol{\oplus}$ \\
\hline $100 / 0$ & $100 / 0$ & 71 & 2300 & $-^{c}$ & $-^{c}$ & 3900 & 1.39 \\
\hline $80 / 20$ & $83 / 17$ & 73 & $-{ }^{d}$ & $-^{c}$ & $-{ }^{c}$ & 3600 & 1.40 \\
\hline $70 / 30$ & $72 / 28$ & 66 & $-{ }^{d}$ & $-^{c}$ & $-{ }^{c}$ & 3600 & 1.44 \\
\hline $50 / 50$ & $50 / 50$ & 71 & $-{ }^{d}$ & 3300 & 1.48 & 3900 & 1.43 \\
\hline $20 / 80$ & $18 / 82$ & 55 & $-{ }^{d}$ & 4100 & 1.38 & 3800 & 1.39 \\
\hline $0 / 100$ & $0 / 100$ & 54 & 4700 & 5800 & 1.27 & 4800 & 1.34 \\
\hline
\end{tabular}

The ${ }^{1} \mathrm{H}$ NMR spectra of oligoGC, oligoSol and oligo(GC-stat-Sol)s with various GCA/SolA ratios were superimposed in Figure 4. The integration of the peaks located at $5.04 \mathrm{ppm}$ attributed to $\mathrm{H}_{(3)}(\mathrm{CH}$ in $\alpha$ position of cyclocarbonate of GC) and at $1.37-1.43 \mathrm{ppm}$ attributed to $\mathrm{H}_{(15,16)}\left(2 \mathrm{xCH}_{3}\right.$ of acetal group) gave the GCA/SolA ratio in oligo(GC-stat-Sol)s. As summarized in Table 2, whatever the cooligomer, the experimental GCA/SolA ratio was consistent with the theoretical one. 


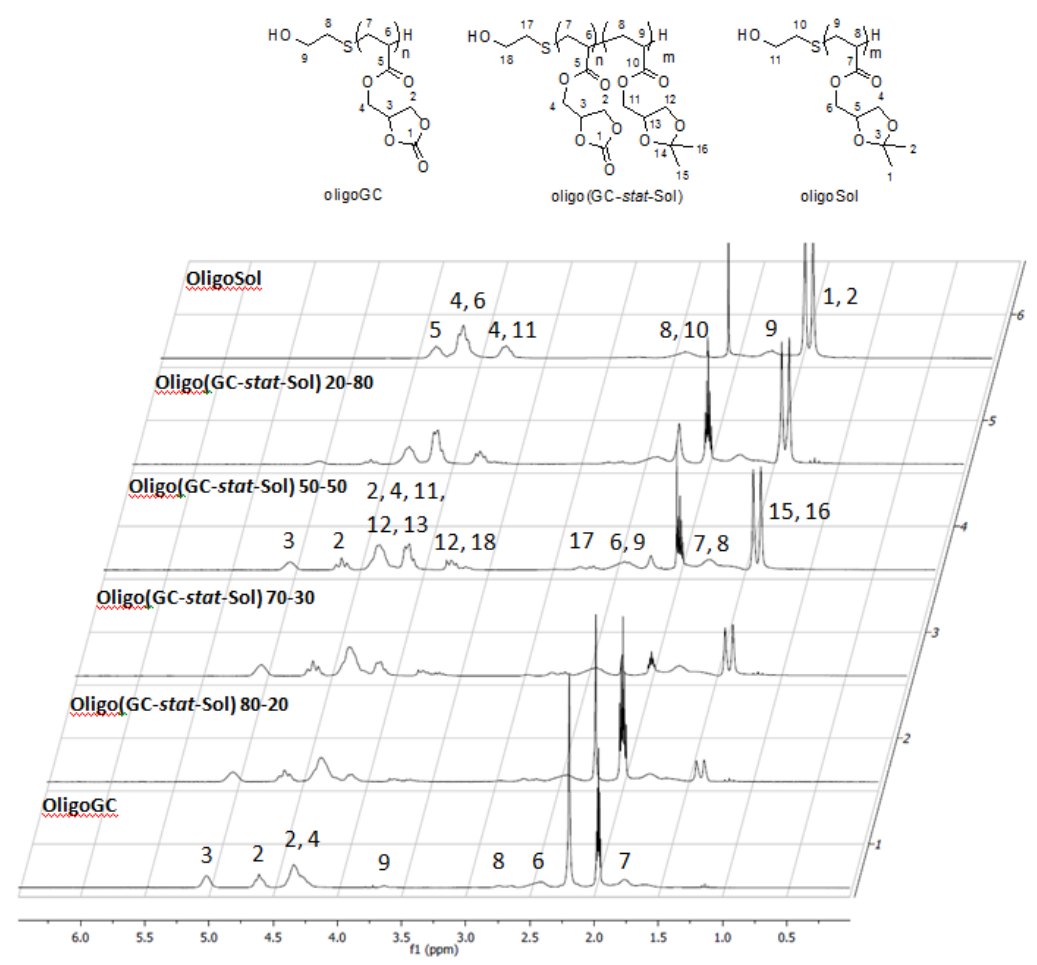

Figure 4. ${ }^{1} \mathrm{H}$ NMR spectra of oligoGC, oligoSol and various oligo(GC-stat-Sol)s after purification $\left(\mathrm{CD}_{3} \mathrm{CN} ; 200 \mathrm{MHz}\right)$.

The yield in oligo(GC-stat-Sol)s decreased with GCA/SolA ratio because of the increase of the solubility brought by SolA units which led to a difficulty to precipitate the oligomer part (54-71\%). The experimental number-average molecular weight of oligomers was determined by SEC in DMF $\left(\mathrm{M}_{\mathrm{n} \text { DMF }}\right)$ and in THF $\left(\mathrm{M}_{\mathrm{n} \text { THF }}\right)$ as summarized in Table 2. All the oligomers exhibited similar molecular weights (around 4000 g.mol ${ }^{-1}$ ) with a narrow dispersity (1.27-1.48). The $\mathrm{M}_{\mathrm{n} \text { THF }}$ deviated from $\mathrm{M}_{\mathrm{n} \text { DMF }}$ and for higher GCA/SolA ratio, $M_{n \text { THF }}$ were lower than $M_{n \text { DMF }}$ whereas the opposite phenomenon occurred for lower ratios. The reactivity ratio of GCA and SolA in oligo(GC-stat-Sol) was impossible to calculate by Finemann-Ross[37], Kelen-Tudos[38, 39], Jaack[40] or Macret[41] methods because of the overlap of the monomer and oligomer ${ }^{1} \mathrm{H}$ NMR signals.

\section{Characteristics of oligo(GC-stat-Sol)s}

The glass transition temperature ( $\mathrm{Tg}$ ) of the various oligomers was determined by DSC technique as illustrated in Figure 5 and Table 3. OligoSol was viscous $\left(\mathrm{Tg}=-30^{\circ} \mathrm{C}\right)$ whereas oligoGC appeared as a white powder $\left(\mathrm{Tg}=48{ }^{\circ} \mathrm{C}\right)$ at room temperature. As expected, the enhancement of oligomers $\mathrm{Tg}$ with the GCA part was observed. It should be noted that the $\mathrm{Tg}$ oligo(GC-stat-Sol) s ranged from $\mathrm{Tg}_{\text {oligosol }}=-30$ to $\mathrm{Tg}_{\text {oligoGC }}=48{ }^{\circ} \mathrm{C}$ depending on the composition. 


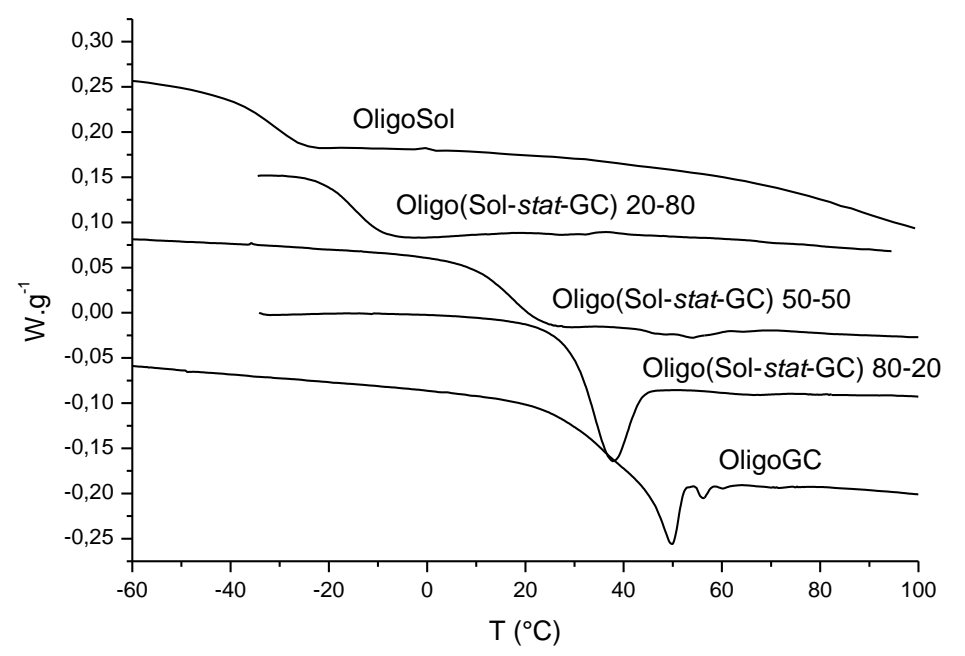

Figure 5. DSC traces of oligoGC, oligoSol and oligo(GC-stat-Sol)s (heating rate: $10{ }^{\circ} \mathrm{C} \cdot \mathrm{min}^{-1}$, second run).

The solubility of the oligo(GC-stat-Sol)s was evaluated for different compositions. The solubility of oligo(GC-stat-Sol)s increased with SolA/GCA ratio. The oligoGC was only soluble in the high polar solvents such as $\mathrm{CH}_{3} \mathrm{CN}$, DMF and DMSO whereas the oligoSol was soluble in almost common organic solvents (Table 3). Thus, the nature of the glycerin protecting group had an influence on the solubility of the oligo(GC-stat-Sol)s knowing that the molecular weights and the end chain functionalities of the latter were identical. Interestingly, the solubility of oligo(GC-stat-Sol)s with various GCA/SolA ratios was intermediate between that of oligoGC and oligoSol. In summary, the incorporation of SolA in GCA structure by cotelomerization improved the GCA solubility in organic solvent.

Table 3. Solubility and Tg values for oligoSol, oligoGC and various oligo(GC-stat-Sol)s.

\begin{tabular}{c|cccccc}
\hline $\mathbf{G C A} /$ SolA & $\mathbf{C H C l}_{\mathbf{3}}$ & $\mathbf{T H F}$ & Acetone & $\mathbf{E t O H}$ & $\mathbf{H}_{2} \mathbf{O}$ & $\mathbf{T g}\left({ }^{\circ} \mathbf{C}\right)$ \\
\hline $100 / 0$ & - & - & - & - & - & 48 \\
$83 / 17$ & - & - & + & - & - & 34 \\
$50 / 50$ & + & + & + & - & - & 17 \\
$18 / 82$ & + & ++ & ++ & + & - & -10 \\
$0 / 100$ & ++ & ++ & ++ & ++ & - & -30 \\
\hline
\end{tabular}

- insoluble; + soluble; ++ spontaneously soluble.

In a last part, the selective hydrolysis of the glycerol-based co-oligomers either by cleavage of the carbonate ring or acetal one was investigated, the question being to know if only one of the two different groups could be cleaved selectively (Scheme 3). In a first step, the hydrolysis of homo- 
oligoGC and homo-oligosol was investigated. The quantitative hydrolysis of the pendant cyclocarbonate groups of oligoGC $\left(\mathrm{M}_{\mathrm{n}}=3900 \mathrm{~g} \cdot \mathrm{mol}^{-1}\right.$, $\left.\mathrm{PDI}=1.39\right)$ was achieved in the presence of pyridine without organic solvent (pyridine/water $(1 / 1), 115{ }^{\circ} \mathrm{C}, 8 \mathrm{~h}$ ) in $78 \%$ yield. As observed for other polymerization processes and oligomers, an uncomplete polymer recovery was observed due to a difficulty to precipitate low molecular weight polymers. The gradual disappearance of $\mathrm{C}=\mathrm{O}$ band relative to cyclocarbonate group $\left(1785 \mathrm{~cm}^{-1}\right)$ versus time was monitored by FTIR spectroscopy and no hydrolysis of $\mathrm{C}=\mathrm{O}(\mathrm{O})$ ester group $\left(1731 \mathrm{~cm}^{-1}\right)$ (Figure 6) was detected. The attempt to replace pyridine by triethylamine failed and the hydrolysis of both ester and cyclocarbonate groups was observed leading to poly(acrylic acid).

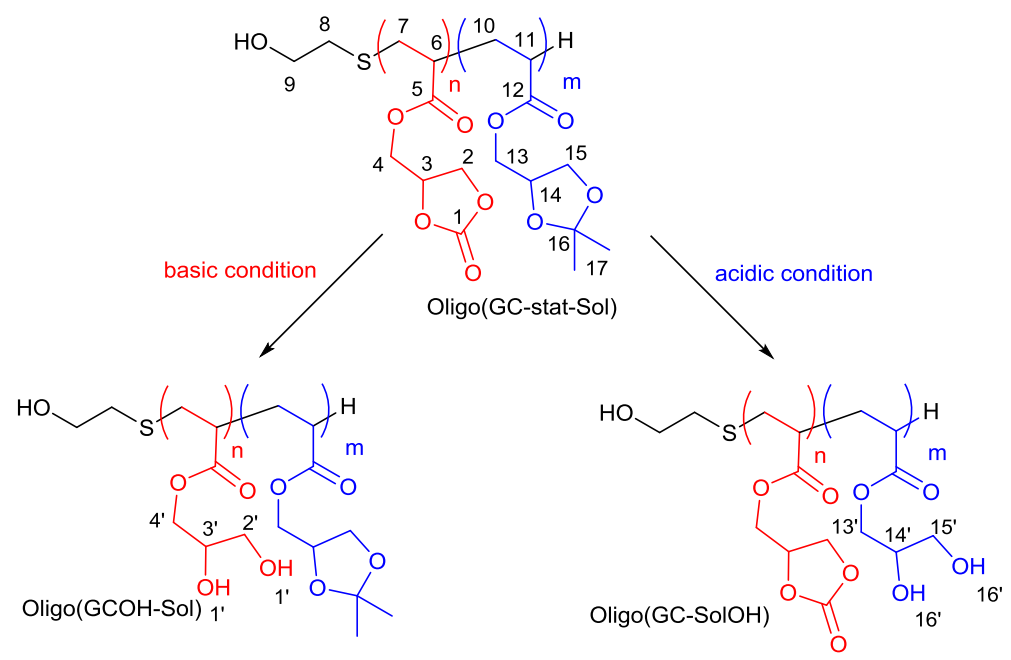

Scheme 3. Orthogonal hydrolysis of oligo(GC-stat-Sol) under acidic $\left(\mathrm{HCl} 1 \mathrm{M}, \mathrm{CH}_{3} \mathrm{CN}, 0{ }^{\circ} \mathrm{C}-\mathrm{RT}, 24\right.$ h, $80 \%$ ) and basic conditions (pyridine/ $\left.\mathrm{H}_{2} \mathrm{O}(1 / 1), 115^{\circ} \mathrm{C}, 8 \mathrm{~h}, 75 \%\right)$.
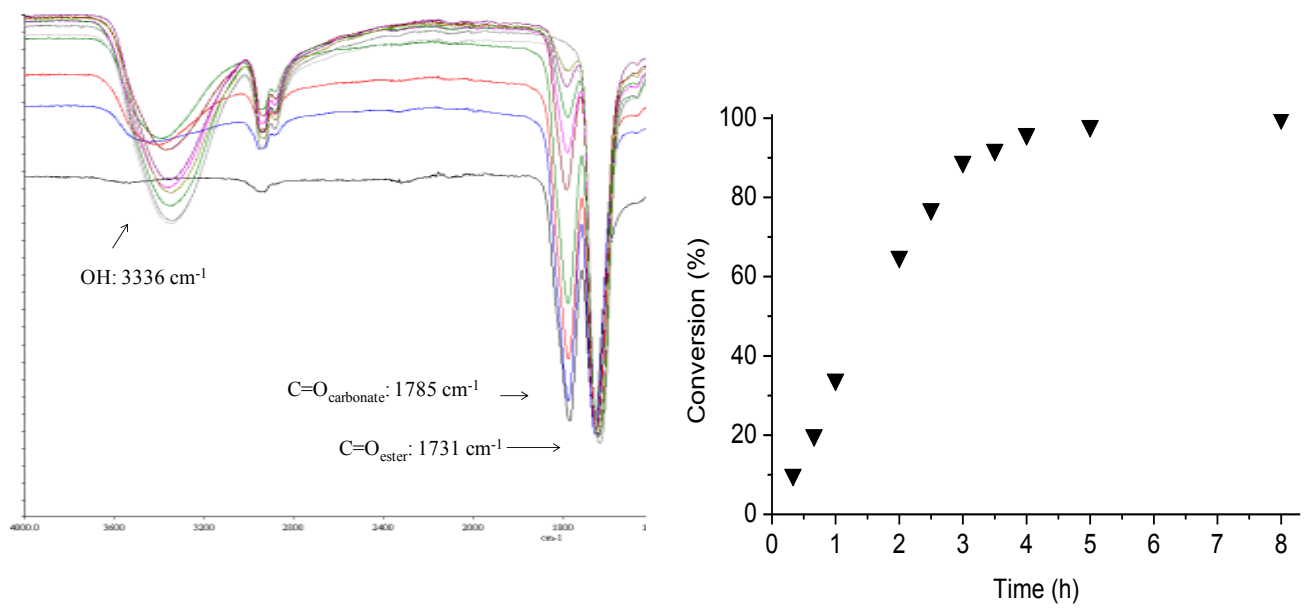

Figure 6. Conversion versus time by FTIR spectroscopy for the hydrolysis of oligoGC under basic condition. 
The structure of hydrolyzed product, oligoOH was confirmed by ${ }^{1} \mathrm{H},{ }^{13} \mathrm{C}$ NMR and MALDI-TOF mass spectroscopies. Two distributions of peaks were observed on the MALDI-Tof spectrum with an interval of 146.1 g.mol ${ }^{-1}$ between two consecutive peaks of the same family corresponding to the molecular weight of the dihydroxyl monomer unit (Supporting Information). This data confirmed the chimio-selectivity between the ester and cyclocarbonate groups during the hydrolysis reaction. Thanks to MALDI-Tof spectroscopy, the nature of oligo end-groups on the main family $(\mathrm{H}-$ and $\mathrm{HOCH}_{2} \mathrm{CH}_{2} \mathrm{~S}$-) was also confirmed (Supporting Information). In the case of oligoSol, the hydrolysis of the acetal group was studied under acidic condition $\left(\mathrm{HCl} 1 \mathrm{M}, \mathrm{CH}_{3} \mathrm{CN}, 0{ }^{\circ} \mathrm{C}-\mathrm{RT}, 24 \mathrm{~h}\right)$. OligoOH $\left(\mathrm{M}_{\mathrm{n}}=4800 \mathrm{~g} \cdot \mathrm{mol}^{-1}, \mathrm{PDI}=1.34\right)$ were produced in good yield (80\%) and the structure was confirmed by ${ }^{1} \mathrm{H},{ }^{13} \mathrm{C}$ NMR and FTIR spectroscopies (Supporting Information). In summary, no hydrolysis of oligoGC and oligoSol occurred under acidic and basic conditions, respectively demonstrating the orthogonal behavior of the hydrolysis of the acetal and cyclocarbonate groups.

Starting from this result, a cotelomer bearing both acetal and cyclocarbonate pendant groups, oligo(GC-stat-Sol) 50/50 ( $\mathrm{M}_{\mathrm{n}}=3900$ g.mol ${ }^{-1}$, PDI=1.43) was selectively deprotected. As expected, the acetal functions of oligo(GC-stat-Sol) were hydrolyzed into oligo(GC-stat-SolOH) under acidic condition $\left(\mathrm{HCl} / \mathrm{CH}_{3} \mathrm{CN}\right)$ whilst the cyclocarbonate groups of the same cotelomer were deprotected under basic condition (pyridine/ $\left.\mathrm{H}_{2} \mathrm{O}\right)$ giving oligo(GCOH-stat-Sol) in good yields 80 and 75\%, respectively. The selective hydrolyses were monitored by NMR experiment with the disappearance of gem-dimethyl $\left(\mathrm{H}_{17}\right)$ of acetal group at $1.37-1.43 \mathrm{ppm}$ (Figure 7). The ring-opening of cyclocarbonate group was also detected with the shift of $\mathrm{H}_{2}$ and $\mathrm{H}_{3}$ signals from 4.67 to $5.15 \mathrm{ppm}$, respectively to 4.1 and $4.3 \mathrm{ppm}$, respectively. Thus, the orthogonal character of the hydrolysis of cyclocarbonate and acetal groups of glycerol-based cotelomers was confirmed.

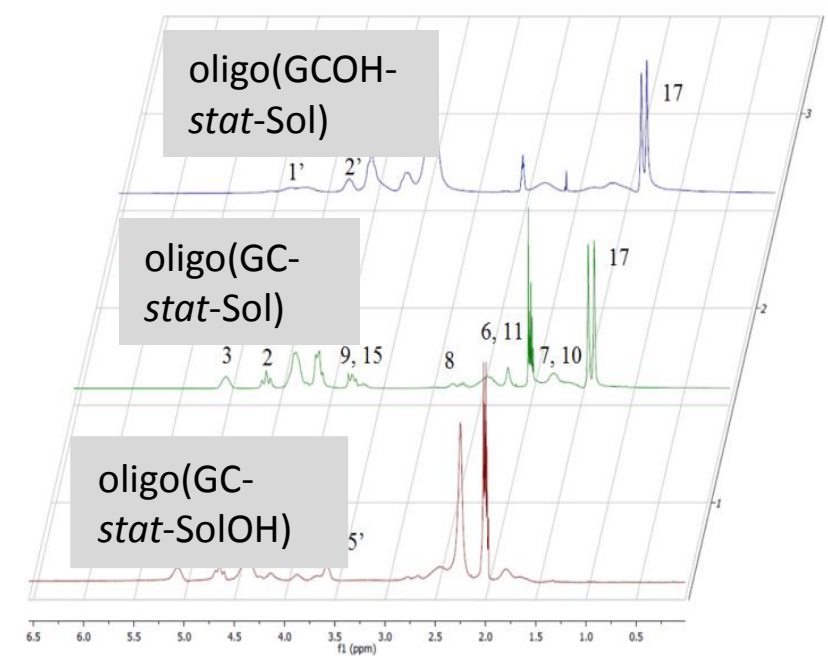

Figure 7. ${ }^{1} \mathrm{H}$ NMR spectra of oligo(GC-stat-Sol), oligo(GCOH-stat-Sol) and oligo(GC-stat-SolOH). 
Finally, the solubility of the glycerol-based (co)telomers was studied in various common organic solvents and water (Table 4). In all organic solvents, oligoSol was soluble whereas oligoGC was insoluble (excepted in $\mathrm{CH}_{3} \mathrm{CN}$ ). However, both oligomers were insoluble in water. In the series of oligo(GC-stat-Sol) derivatives, contrasting behavior were detected. In all organic solvents and water, the oligo(GCOH-Sol) was completely soluble whereas the oligo(GC-SolOH) was insoluble. Thus, the incorporation of acetal group in oligomer structure enhanced the solubility whereas cyclocarbonate group decreased it.

Table 4. Solubility of various glycerol-based (co)telomers.

\begin{tabular}{c|cccccc}
\hline Oligomer & $\mathbf{C H C l}_{\mathbf{3}}$ & THF & Acetone & $\mathbf{E t O H}$ & $\mathbf{C H}_{3} \mathbf{C N}$ & $\mathbf{H}_{2} \mathbf{O}$ \\
\hline Oligo(GC) & - & - & - & - & ++ & - \\
Oligo(Sol) & + & ++ & ++ & ++ & ++ & - \\
Oligo(GC-stat-Sol) & + & + & + & - & ++ & - \\
Oligo(GC-stat-SolOH) & - & - & - & - & - & - \\
Oligo(GCOH-stat-Sol) & + & + & ++ & ++ & ++ & + \\
Oligo(OH) & - & - & - & - & - & ++ \\
\hline
\end{tabular}

- insoluble; + soluble; ++ instantaneously soluble. 


\section{Conclusion}

In this contribution, we report the synthesis of glycerol-based oligomers from acrylate monomers bearing carbonate and acetal groups. These materials were synthesized in good yield by free-radical telomerization. The efficiency of 2-mercapthoethanol as chain transfer agent was shown with both monomers and telomerization process allowed the synthesis of low molecular weight polymers. The chain end functionalities of oligomers were characterized using MALDI Tof MS measurements. The cotelomerization lead to polymers bearing both carbonate and cetal goups with glass transition temperature ranging from - 30 to $48{ }^{\circ} \mathrm{C}$. The oligoGC solubility was improved thanks to the incorporation of oligoSol in oligo(GC-stat-Sol) by cotelomerization in common organic solvents. The selective hydrolyses of cyclocarbonate or acetal protective groups of glycerol based oligomers were demonstrated under acidic and basic conditions. To the best of our knowledge, this is a first report concerning the switchable hydrolysis of oligomers from glycerol based acrylates. The orthogonal aspect of the hydrolysis was developed with (co)telomers bearing both cyclocarbonate and acetal pendant groups. By this methodology, functionalized (co)telomers were synthesized with alcohol, cyclocarbonate and/or acetal pendant groups. The influence of each one on Tg value and solubility in water and in various organic solvents was clearly demonstrated. Acetal groups improved the solubility and decreased the Tg value of the glycerol-based (co)telomers whereas the cyclocarbonate pendant group induced the reverse trend.

\section{Acknowledgement}

The authors gratefully acknowledge ONIDOL for their financial support. 


\section{References}

[1] Y.G. Zheng, X.L. Chen, Y.C. Shen, Commodity Chemicals Derived from Glycerol, an Important Biorefinery Feedstock, Chemical Reviews 108(12) (2008) 5253-5277.

[2] M. Aresta, A. Dibenedetto, F. Nocito, C. Ferragina, Valorization of bio-glycerol: New catalytic materials for the synthesis of glycerol carbonate via glycerolysis of urea, Journal of Catalysis 268(1) (2009) 106-114.

[3] A. Behr, J. Eilting, K. Irawadi, J. Leschinski, F. Lindner, Improved utilisation of renewable resources: New important derivatives of glycerol, Green Chemistry 10(1) (2008) 13-30.

[4] C.H.C. Zhou, J.N. Beltramini, Y.X. Fan, G.Q.M. Lu, Chemoselective catalytic conversion of glycerol as a biorenewable source to valuable commodity chemicals, Chemical Society Reviews 37(3) (2008) 527-549.

[5] D. Bergemann, LaborPraxis 34 (2010) 46-48.

[6] Z. Mouloungui, S. Pelet, Study of the acyl transfer reaction: Structure and properties of glycerol carbonate esters, European Journal of Lipid Science and Technology 103(4) (2001) 216-222.

[7] A. Vora, K. Singh, D.C. Webster, A new approach to 3-miktoarm star polymers using a combination of reversible addition-fragmentation chain transfer (RAFT) and ring opening polymerization (ROP) via "Click" chemistry, Polymer 50(13) (2009) 2768-2774.

[8] G. Rokicki, P. Rakoczy, P. Parzuchowski, M. Sobiecki, Hyperbranched aliphatic polyethers obtained from environmentally benign monomer: glycerol carbonate, Green Chemistry 7(7) (2005) 529-539.

[9] P. Klug, F.M. Pilz, G. Kluth, P. Steffanut, M. Meder, Cosmetic or pharmaceutical compositions, emulsions comprinsing modified polysiloxanes with at least one carbonate group, Chemical Indexing Equivalent to 149:408948 (EP)2009.

[10] J. Britz, W.H. Meyer, G. Wegner, Blends of poly(meth)acrylates with 2-Oxo-(1,3)dioxolane side chains and lithium salts as lithium ion conductors, Macromolecules 40(21) (2007) 7558-7565.

[11] N.A.A. Rossi, R. West, Silicon-containing liquid polymer electrolytes for application in lithium ion batteries, Polymer International 58(3) (2009) 267-272.

[12] Z. Zhang, L.J. Lyons, R. West, K. Amine, R. West, Synthesis and ionic conductivity of mixed substituted polysiloxanes with oligoethyleneoxy and cyclic carbonate substituents, Silicon Chemistry 3 (2007) 259-266.

[13] Z.Y. Zhu, A.G. Einset, C.Y. Yang, W.X. Chen, G.E. Wnek, Synthesis of polysiloxanes bearing cyclic carbonate side-chains - dielectric-properties and ionic conductivities of lithium triflate complexes, Macromolecules 27(15) (1994) 4076-4079.

[14] M.O. Sonnati, S. Amigoni, E.P.T. de Givenchy, T. Darmanin, O. Choulet, F. Guittard, Glycerol carbonate as a versatile building block for tomorrow: synthesis, reactivity, properties and applications, Green Chemistry 15(2) (2013) 283-306.

[15] D.C. Webster, Cyclic carbonate functional polymers and their applications, Progress in Organic Coatings 47(1) (2003) 77-86.

[16] G.F. Dalelio, T. Huemmer, Preparation and polymerization of some vinyl monomers containing 2-oxo-1,3-dioxolane group, Journal of Polymer Science Part A: Polymer Chemistry 5 (1967) 307.

[17] H.E. Katz, Preparation of soluble poly(carbonyldioxyglyceryl methacrylate), Macromolecules 20(8) (1987) 2026-2027.

[18] J.C. Brosse, D. Couvret, S. Chevalier, J.P. Senet, Acrylic-monomers containing a cyclic carbonate function .1. synthesis and polymerization, Makromolekulare Chemie Rapid Communications 11(3) (1990) 123-128.

[19] N. Kihara, T. Endo, Synthesis and reaction of polymethacrylate bearing cyclic carbonate moieties in the side-chain, Makromolekulare Chemie Macromolecular Chemistry and Physics 193(6) (1992) $1481-1492$.

[20] C. Decker, K. Moussa, A new class of highly reactive acrylic monomers. 1. Light-induced polymerization, Makromolekulare Chemie-Rapid Communications 11(4) (1990) 159-167.

[21] C. Decker, K. Moussa, A new class of highly reactive acrylic monomers. 2. Light-induces copolymerization with difunctional oligomers, Makromolekulare Chemie-Macromolecular Chemistry and Physics 192(3) (1991) 507-522. 
[22] F. Camara, S. Caillol, B. Boutevin, Free radical polymerization study of glycerin carbonate methacrylate for the synthesis of cyclic carbonate functionalized polymers, Eur. Polym. J. 61 (2014) 133-144.

[23] V. Besse, F. Camara, C. Voirin, R. Auvergne, S. Caillol, B. Boutevin, Synthesis and applications of unsaturated cyclocarbonates, Polym. Chem. 4(17) (2013) 4545-4561.

[24] P.D. Pham, S. Monge, V. Lapinte, Y. Raoul, J.J. Robin, Synthesis of surfactants by polymerization of glycerol (meth)acrylates with fatty acids derivatives as chain ends, J. Mater. Sci. 52(2) (2017) 968-980.

[25] B. Boutevin, G. David, C. Boyer, Advances in Polymer Science 206 (2007) 31-135.

[26] B. Boutevin, Y. Pietrasanta, Comprehensive Polymer Science, Eastmond, G. C.; Ledwith, A.; Russo, S.; Sigwalt, P., Eds., Pergamon, NY, 1989.

[27] S. Monge, J. Selambarom, J.P. Roque, A.A. Pavia, Synthesis of precursors of iodine-labeled multifunctional ligands containing 2-nitroimidazole for the detection of hypoxic tissues and/or tumors, Tetrahedron 57(50) (2001) 9979-9987.

[28] C. Boyer, G. Boutevin, J.J. Robin, B. Boutevin, Study of the telomerization of dimethylaminoethyl methacrylate (DMAEMA) with mercaptoethanol. Application to the synthesis of a new macromonomer, Polymer 45(23) (2004) 7863-7876.

[29] C. Boyer, G. Boutevin, J.J. Robin, B. Boutevin, Synthesis of macromonomers of acrylic acid by telomerization: Application to the synthesis of polystyrene-g-poly(acrylic acid) copolymers, Journal of Polymer Science Part A: Polymer Chemistry 45(3) (2007) 395-415.

[30] M. Teodorescu, M. Dimonie, I. Cerchez, Free-radical copolymerization of methyl methacrylate with styrene in the presence of 2-mercaptoethanol, European Polymer Journal 35(2) (1999) 247-252.

[31] R.A. Gregg, D.M. Alderman, F.R. Mayo, Chain transfer in the polymerization of styrene .5. polymerization of styrene in the presence of mercaptans, Journal of the American Chemical Society 70(11) (1948) 3740-3743.

[32] J.L. OBrien, F. Gornick, Chain transfer in the polymerization of methyl methacrylate .1. transfer with monomer and thiols - the mechanism of the termination reaction at 60-degrees, Journal of the American Chemical Society 77(18) (1955) 4757-4763.

[33] F. Pardal, V. Lapinte, J.J. Robin, Kinetics of cotelomerization of 3-(trimethoxysilyl)propyl methacrylate and perfluorodecylacrylate, European Polymer Journal 45(4) (2009) 1198-1207.

[34] G. Kostov, B. Ameduri, S.M. Brandstadter, Radical telomerization of 3,3,3-trifluoropropene with diethyl hydrogen phosphonate: Characterization of the first telomeric adducts and assessment of the transfer constants, J. Fluor. Chem. 128(8) (2007) 910-918.

[35] F. Pardal, V. Lapinte, J.J. Robin, Modification of Silica Nanoparticles by Grafting of Copolymers Containing Organosilane and Fluorine Moities, Journal of Polymer Science Part A: Polymer Chemistry 47(18) (2009) 4617-4628.

[36] C. Loubat, B. Boutevin Macromol. Chem. Phys. 201 (2000) 2853-2860.

[37] M. Fineman, S.D. Ross, Linear method for determining monomer reactivity ratios in copolymerization, Journal of Polymer Science 5(2) (1950) 259-262.

[38] T. Kelen, F. Tudos, Analysis of the Linear Methods for Determining Copolymerization Reactivity Ratios. I. A New Improved Linear Graphic Method Journal of Macromolecular Science: Pure and Applied Chemistry 9 (1975) 1-27.

[39] T. Kelen, F. Tudos, B. Turcsanyi, Analysis of linear methods for determining co-polymerization reactivity ratios .4. comprehensive and critical re-examination of carbocationic co-polymerization data, Journal of Polymer Science Part A: Polymer Chemistry 15(12) (1977) 3047-3074.

[40] V. Jaacks, Novel method of determination of reactivity ratios in binary and ternary copolymerizations, Makromolekulare Chemie 161(NOV) (1972) 161.

[41] M. Macret, G. Hild, Hydroxyalkyl methacrylates - kinetic investigations of radical polymerizations of pure 2-hydroxyethyl methacrylate and 2,3-dihydroxypropyl methacrylate and the radical copolymerization of their mixtures, Polymer 23(1) (1982) 81-90. 


\section{Figures captions}

Figure 1. Consumption ( $\alpha$ ) of ME and monomer versus time ( monomer, $\bigcirc$ telogen) for the polymerization of (a) GCA $\left(\mathrm{R}_{0}=0.1\right)$ and of (b) SolA $\left(\mathrm{R}_{0}=0.1\right)$.

Figure 2. $\operatorname{Ln}\left([\mathrm{ME}]_{0} /[\mathrm{ME}]_{\mathrm{t}}\right)$ versus $\left.\operatorname{Ln}(\mathrm{M}]_{0} /[\mathrm{M}]_{\mathrm{t}}\right)$ for the polymerization of (a) GCA and (b) SolA for different $\mathrm{R}_{0}=(\boldsymbol{\square} 0.05, \bigcirc 0.1, \boldsymbol{\Delta} 0.2, \nabla 0.3)$.

Figure 3. MALDI-Tof MS spectra of (a) oligoGC and (b) oligoSol. Matrix: $\alpha$-cyano-4hydroxycinamic acid (HCCA) with NaI.

Figure 4. ${ }^{1} \mathrm{H}$ NMR spectra of oligoGC, oligoSol and various oligo(GC-stat-Sol)s after purification. $\left(\mathrm{CD}_{3} \mathrm{CN} ; 200 \mathrm{MHz}\right)$.

Figure 5. DSC traces of oligoGC, oligoSol and oligo(GC-stat-Sol)s. Heating rate: $10{ }^{\circ} \mathrm{C} \cdot \mathrm{min}^{-1}$, second run.

Figure 6. Conversion versus time by FTIR spectroscopy for the hydrolysis of oligoGC under basic condition.

Figure 7. ${ }^{1} \mathrm{H}$ NMR spectra of oligo(GC-stat-Sol), oligo(GCOH-stat-Sol) and oligo(GC-stat-SolOH). 